\title{
Una censura «a bulto»: la prohibición inquisitorial de La fianza satisfecha, de Lope ${ }^{\top}$ \\ An offhanded censorship: the Inquisitorial Prohibition of Lope de Vega's La fianza satisfecha
}

\section{Héctor Urzáiz}

Universidad de Valladolid

ESPAÑA

urzaiz@fyl.uva.es

[Hipogrifo, (issn: 2328-1308), 5.1, 2017, pp. 445-463]

Recibido: 30-11-2015 / Aceptado: 23-12-2015

DOl: http://dx.doi.org/10.13035/H.2017.05.01.29

Resumen. Estudio de la prohibición inquisitorial de una obra atribuida a Lope de Vega en el siglo XVIII. Se trata de La fianza satisfecha, una comedia de calidad discutida (la crítica tradicional la juzga muy negativamente) y de paternidad dudosa. Fue denunciada inicialmente al Santo Oficio de Logroño (1781), después al de Barcelona (1798), y finalmente fue prohibida e incluida en el Índice de libros prohibidos de la Inquisición (1801). El caso generó una larga y bastante áspera discusión entre los censores inquisitoriales. En este trabajo se transcribe el expediente conservado en el Archivo Histórico Nacional, que solo se conocía parcialmente por haber estado durante mucho tiempo desgajado en dos partes e inédito en español.

Palabras clave. Teatro, Siglo de Oro, Lope de Vega, censura, Inquisición, Índice de libros prohibidos, siglos XVII-XIX.

Abstract. This paper analyzes the inquisitorial prohibition of Lope de Vega's The fianza satisfecha at the end of the eighteenth century. Criticism has judged very negatively this comedia, whose authorship is uncertain. The fianza satisfecha was denounced to the Inquisition (Logroño, 1781; Barcelona, 1798) and included in the

1. Este trabajo es fruto del proyecto de investigación «CLEMIT-Base de datos integrada del teatro clásico español» (financiado por el Ministerio de Economía y Competitividad/FEDER, UE, FFI2015-65197-C33-P). 
Index librorum prohibitorum (1801) after a long and rough discussion among the censors. The details of this discussion are set out in an almost unknown document (Archivo Histórico Nacional, Madrid) whose transcription is also carried out in this paper.

Keywords. Theater, Spanish Golden Age, Lope de Vega, Censorship, Inquisition, Index of forbidden books, XVII-XIXth centuries.

De pocas comedias se han dicho cosas tan negativas como de La fianza satisfecha, tanto por parte de sus antiguos censores como de los estudiosos posteriores; incluso en tiempos recientes y lejos de España ha provocado grandes polémicas su puesta en escena ${ }^{2}$. Esta comedia (atribuida sin mucha seguridad a Lope de $\mathrm{Vega}^{3}$ ) fue examinada durante veinte años (en dos fases) por la Inquisición hasta ser finalmente prohibida, no sin haberse contrapuesto antes las opiniones de diferentes religiosos, que se enredaron en curiosas disquisiciones. Y la crítica literaria ha sido inclemente con esta pieza; Menéndez Pelayo, por ejemplo, hablaba de «escenas increíbles y repugnantes, que ningún público del mundo toleraría hoy; y no sólo compromete en cierto modo la Majestad Divina [...], sino que toca muchas veces en la caricatura». Bien es cierto que en parte culpaba de ello al texto conservado

en ejemplares sueltos del siglo pasado, lastimosamente estragados con intercalaciones que, por su estilo hinchado y crespo, no pueden ser de Lope, y al mismo tiempo con notoria falta de muchos versos [...] Quizá ninguna de las comedias de Lope padeció tanto como ésta en manos de bárbaros impresores y comediantes famélicos. El texto que leemos parece una refundición groseramente estropeada4 ${ }^{4}$

También Ángel Valbuena se despachó a gusto con La fianza satisfecha: «Una concesión del improvisador Lope a una desbordada e irresponsable fantasía [...] Leonido es un esperpento, una exageración absurda del tipo de la maldad, parricida, incestuoso y anticristiano, que luego, al arrepentirse, muere en la cruz y repitiendo -ivaya un parangón edificante!- las palabras del Redentor» ${ }^{5}$.

Hay, sin embargo, alguna opinión más favorable, como la del conde de Shack, quien reconocía también los excesos de La fianza satisfecha («La fantasía del poeta se desborda en ella: no escasa parte es tan hueca como arbitraria») pero al mismo tiempo encontraba estimulante la carga poética del drama: «Tales extravagancias son compensadas con tantos rasgos de la más acendrada poesía, que nos obligan

2. Ver en Álvarez Faedo, 2000, lo ocurrido en los teatros londinenses en 1966, con la adaptación al inglés que hizo John Osborne (A Bond Honoured).

3. «Although we are not entirely convinced that Lope de Vega wrote La fianza satisfecha, we are inclined to believe that he did», dicen sus editores modernos: Whitby y Anderson, 1971, p. 20.

4. Menéndez Pelayo, 1921, pp. 95-96.

5. Valbuena Prat, 1931, p. 25. 
a rendir homenaje al genio del poeta hasta en sus extravíos» ${ }^{6}$. También Manuel Cañete encontraba algunos trazos propios de un «pincel digno de Shakespeare» y ciertos «delicados rasgos de ternura»?

Pero sin duda quien menos aprecio tuvo por La fianza satisfecha fue la Inquisición, que la prohibió a finales del siglo XVIII (cuando la obra había acumulado ya un elevado número de ediciones ${ }^{8}$ ). Antes de llegar a ese punto se recabaron las opiniones de muchos calificadores inquisitoriales; sus juicios componen un expediente nutrido y muy interesante, que se conserva en el Archivo Histórico Nacional (AHN). Dio la primera noticia sobre este expediente Antonio Paz y Mélia a comienzos del siglo XX, junto con unos breves apuntes sobre las objeciones del Santo Oficio a la obra de Lope:

El censor halla «muchas blasfemias horrorosísimas contra Dios, muchas irreverencias de un hijo contra sus padres y muchas otras maldades cometidas por el mismo hijo, aunque es verdad que en la última jornada se halla su conversión después de unos ecos de Cristo, impropios de este Señor...», por lo que debe prohibirse la representación y lectura?

Paz fechaba el expediente en 1798 (como vamos a ver, el caso arrancó en realidad en 1781) y añadía que fue «prohibida por perjudicial a las buenas costumbres e inductiva a una vana confianza, al repetir el héroe "Que lo pague Dios por mí", lo que da motivo al título. Entre los censores de la comedia firma D. Joaquín Lorenzo Villanueva» ${ }^{10}$; poco más se reseñaba en su escueta nota.

En 1935, María Jiménez Salas volvería al archivo inquitorial para recordar que el documento en cuestión seguía sin ser estudiado: «Expediente inédito, a lo que creo»"1. Lo hacía en «Un comentario más a La fianza satisfecha», unas páginas dedicadas a reivindicar los valores y aciertos literarios de esta comedia frente a los muy negativos juicios que sobre ella habían emitido los eruditos tradicionales: «La primera lectura de La fianza satisfecha deja, a lo que parece, impresión de extrañeza y desagrado. Después, suele venir la reacción favorable; una relectura conduce, quizá, al entusiasmo». Del tono de aquellas páginas pueden dar buena idea estas palabras sobre el episodio de censura sufrido por la comedia: «La fianza fue condenada por la Santa Inquisición a fines del siglo XVIII; aquella edad y el Santo Oficio

6. Shack, Historia de la literatura y del arte dramático en España, t. III, p. 170.

7. Cañete, Sobre el drama religioso español antes y después de Lope de Vega, p. 398

8. Hay bastantes sueltas del XVIII, aunque curiosamente no hay testimonios críticos fechables en el XVII (no fue incluida en ninguna parte de comedias). Se conserva un manuscrito que Paz y Mélia fechaba en el XVIII, donde se atribuye a Calderón (BNE, Ms. 16.840). No hay datos que permitan afirmar que la obra tuviera problemas con la censura en el XVII, aunque tampoco quedan registros de representaciones. 9. Paz y Mélia, 1907, p. 91.

10. Paz y Mélia, 1907, p. 92. Escritor e historiador ilustrado, Villanueva (Játiva, 1757-Dublín, 1837) fue un religioso de talante liberal, defensor del regalismo eclesiástico y cercano a los jansenistas. Miembro de la Real Academia de la Historia y de la Real Academia Española, fue también bibliotecario de esta última. 11. Jiménez Salas, 1935, p. 598, n. 23. 
estaban de agonía y testamento, y la prohibición de la comedia de Lope es una última voluntad» ${ }^{12}$.

Jiménez Salas daba cuenta también de la «sentencia descarnada» del Santo Oficio y algunos pocos detalles del expediente inquisitorial. Pero, al igual que Paz y Mélia, solo parece haber conocido la segunda parte del expediente (incoada en Barcelona en 1798), no la primera, surgida tras una denuncia a la Inquisición de Logroño en 1781.

Así lo advirtieron William Whitby y Robert Anderson, quienes editaron en 1971 La fianza satisfecha: «María Jiménez Salas discusses the second process in some detail but apparently did not know about the earlier process» ${ }^{13}$. Parece que ello pudo deberse a que el caso estaba desgajado en diferentes expedientes del AHN y no se reunificó hasta mediados del siglo XX. En mitad del legajo hay una hoja con una nota de mano más moderna que señala: "La fianza satisfecha-comedia de Lope de Vega. Impreso que pasa a Carp. 1 doc. 13»; la función de esta nota es avisar de la localización actual en el AHN del ejemplar impreso de la comedia que se utilizó para estudiar el caso $^{14}$.

Tal vez pudo influir en alguna medida la confusión del título de la obra que se observa en algunos trabajos modernos. En 1997, Antonio Roldán dedicó un artículo a la prohibición inquisitorial de la comedia El diablo predicador, de Belmonte Bermúdez, donde daba cuenta de algunas coincidencias entre ese caso y el que nos ocupa de La fianza satisfecha, a la que se refiere aquí como La venganza satisfecha (en otros trabajos suyos la nombra correctamente):

Quisiera, para concluir, señalar las coincidencias que existen entre El Diablo Predicador y La venganza satisfecha, desde el punto de vista de sus peripecias inquisitoriales; ya he señalado anteriormente que la obra de Lope fue magistralmente defendida. Y ahora debo añadir que también había sido denunciada y condenada en el Tribunal de Logroño y posteriormente calificada en el Tribunal de Corte, entre otros, por Fr. Antonio de la Santísima Trinidad que ha aparecido en el expediente de El Diablo Predicador; y -curioso paralelismo-, la Suprema dejó en suspenso la sentencia de Logroño sobre La venganza [...] [Belmonte] se vio al final unido con el Monstruo en un mismo e infamante mausoleo: el Apéndice de

12. Jiménez Salas, 1935, p. 585.

13. Whitby y Anderson, 1971, p. 49, n. 1. Dicen también que «Jiménez Salas reproduces all of the arguments of the two first censors, but only sums up those of the Junta, quoting a few lines from their censure [...] Paz y Melia gives briefer excerpts from the file of the same process» (p. 57).

14. Lleva la signatura INQUISICIÓN, MPD. 13. Según hemos comprobado, este impreso no presenta ninguna marca de revisión salvo la que hay (\#) junto a los versos que dicen: «Intenté a mi propia hermana / deshonrar; y quiso el cielo / (mas qué digo: yo lo quise)». Es extraño que el impreso que se utilizara en el largo y enconado proceso de revisión de La fianza satisfecha no presente más marcas; así que cabe suponer que se usara más de un ejemplar. Sin embargo, como veremos más adelante, alguno de los calificadores inquisitoriales se quejó precisamente de que no se habían marcado en el texto los pasajes concretos por los que se pedía su prohibición. 
los Edictos publicados desde el Índice de 1790, el de D. Agustín Rubín de Cevallos, hasta $1819^{15}$.

Pocos años después, Ángel Alcalá daba una escueta noticia sobre la prohibición de esa comedia llamándola también La venganza satisfecha (no sabemos si arrastra el error de Roldán, ya que no lo cita):

Lope de Vega. La venganza satisfecha. Prohibida por Ed. 18/III/1801 (leg. 4506-4) y luego en el Supl. II, p. 53. La fácil salvación del malvado protagonista no resulta aceptable a los censores, divididos además sobre si aceptar o no como irrisión herética o como muestra de piedad ciertas expresiones abusivas $^{16}$.

La mencionada edición de Whitby y Anderson de La fianza satisfecha (una edición académica en inglés) incluye un estudio previo que contiene unas interesantes y muy razonadas páginas dedicadas a este expediente. Sin embargo, su solvente análisis de la diatriba censoria sobre La fianza satisfecha solo va acompañado de la transcripción de algunos pocos fragmentos del extenso expediente inquisitorial (con algunos errores en la identificación de nombres de personas y lugares). La glosa que hacen Whitby y Anderson de los documentos suele ser atinada, pero sin duda el principal punto de interés está en los comentarios originales de los censores, a cuya transcripción (si no completa, sí bastante extensa) dedicaremos las próximas páginas ${ }^{17}$.

\section{«LA COMEDIA SE ECHA, AUNQUE VENGA CRISTO EN CARNE HUMANA»}

El expediente inquisitorial de La fianza satisfecha arranca a partir de la denuncia ante el Santo Oficio de Logroño que el 30 de junio de 1781 hizo el comisario inquisitorial Francisco Ventura del Mazo ${ }^{18}$ desde Meruelo (Cantabria), tras haberse producido graves incidentes de orden público en relación con una representación de la comedia «el jueves víspera de San Pedro»:

15. Roldán, 1997, p. 419. Para este interesante caso ver la ficha de El diablo predicador en la base de datos del proyecto CLEMIT («Censuras y licencias en manuscritos e impresos teatrales»), disponible en acceso libre en internet (http://buscador.clemit.es/).

16. Alcalá, 2001, pp. 100-101.

17. La transcripción completa del expediente, que no tiene cabida aquí, se debe a Unai Rojo Fernández (Universidad de Valladolid) y puede leerse también en la base de datos CLEMIT.

18. «Don Francisco Venturo del Ulazo», dicen Whitby y Anderson, quienes señalan que «Meruelo, included in the judicial district of Santoña, lies to the west of that town, in the direction of Santander» (1971, p. 48). Pero se trata de Francisco Ventura del Mazo, «natural del lugar del Meruelo, diócesis de Burgos, fue recibido en 5 de diciembre de 1733. Llevó el beneficio del lugar» (Rojas y Contreras, Historia del colegio viejo de San Bartolomé, mayor de la célebre Universidad de Salamanca, p. 1012). A partir de aquí obviamos otras discrepancias que tenemos con su transcripción de los textos. 
Ilustrísimo Señor:

Remito a V.S. la comedia intitulada La fianza satisfecha [...] en la que se descubrió un hombre crucificado desnudo de medio arriba, cuyo espectáculo causó bastante escándalo.

Después que trajese otrora la comedia de El renegado de Carmona, que remití a V.S., sabiendo los curas de aquella villa que los comediantes [propalaban que] habían de sacar los bancos grandes de la iglesia para hacer el tablado para representarla y que, si no consentían en ello, lo habían de hacer con violencia, acudieron los curas al tribunal eclesiástico de Santander con memorial al señor Provisor [...] fue el notario a la notificación y, habiéndolo hecho saber a los curas y alcalde, dijeron estaban prontos; y el alcalde firmó su respuesta. Luego que se extendió esta noticia vinieron los vecinos de tropel y [...] trataron al notario vilmente de palabras y acciones, con desprecio del tribunal eclesiástico y del auto, asegurando que se había de echar la comedia (y hubo persona que dijo que aunque viniera Cristo en carne humana); de modo que era tal la inquietud y alboroto de la gente que estaban ciegos y resueltos a hacer desatinos, por lo que iba a haber venido aquí el mismo alcalde, con el notario, a contarme los lances acaecidos y que no se atrevía a dar el auxilio porque habían de resultar consecuencias infelices, por evitar algún motivo, me pareció conveniente suspender las diligencias.

Todo esto pasó el jueves víspera de San Pedro que se había de echar la comedia, y el mismo día de San Pedro por la mañana se fueron a la iglesia y, perdiendo el respeto al templo y sacerdotes que se oponían a que se sacasen los bancos, sin hacer caso de requerimientos ni razones, violentamente sacaron los bancos, hicieron el tablado y representaron la comedia.

Deseo saber si las dos merecen la pena de prohibirse. Nuestro Señor, que a V.S. etc. Meruelo y junio 30 de 1781.

[?] a V.S. su más [¿rendido?] súbdito y cap.n[?],

Don Francisco Ventura del Mazo. [rúbrica]

Señores inquisidores de la Inquisición de Logroño.

El Santo Oficio logroñés acusó recibo de la denuncia el 6 de julio y el día 11 remitió el caso a dos calificadores inquisitoriales («Señores Entero [y] Ortega. / A sus antecedentes y al señor Inquisidor Fiscal. [rúbrica]»), cuyas censuras resultaron muy discrepantes; el primero emitió un breve informe negativo, mientras que el segundo se explayó bastante más para concluir que no solo no debía prohibirse, sino que su representación o lectura serían muy provechosas:

\section{Ilustrísimo Señor:}

Lei con reflexión la comedia [...] y hallé que toda ella está sembrada de proposiciones heréticas, erróneas, blasfemas, impías, temerarias, escandalosas, piarum aurium ofensivas y contrarias, respectivamente, a la Sagrada Escritura, dogmas católicos y aversivas de los Santos Sacramentos. Así lo siento, salvo el mayor dictamen de V.S.I. [...]. San Francisco de Logroño, y 24 de julio de 1781.

Fray José Ruiz Pascual. [rúbrica] 
He leído la comedia [...] y juzgo no contenga dicho ni hecho alguno por el que se puede presumir que su lectura sea perjudicial; sino, antes bien, muy útil y muy conducente a la mayor honra y gloria de Dios, provecho y perfección de los que la lean u oigan representar.

En lo que a primera vista parecerá acaso que podrá tener algún inconveniente, conceptúo que será en la pintura que el autor hace de Leonido en la primera y segunda jornada [...] Pero no obstante juzgo no haya que temer ningún inconveniente porque, con el retrato que en la tercera jornada hace del mismo Leonido ya convertido de Dios y puesto por su autor en una cruz llorando amargamente sus impiedades y blasfemias, me parece se desvanecen todos [...].

Tal me persuado que sería la intención del autor de esta comedia, a imitación de muchos hombres muy doctos y muy piadosos que, con el mismo fin, se esmeraron en sacar a la luz las vidas de algunos hombres que, habiendo sido primero monstruos de la culpa, ayudados de Dios se hicieron después prodigios de la gracia. Tales fueron un San Pablo, un San Agustín, un San Guillermo, un San Pedro Armengol y otros muchos; y así como los libros en que se estamparon las vidas de estos andan en manos de todos, y todos las leen sin temor alguno de su ruina, así también soy de sentir que se deje correr libremente la comedia intitulada La fianza satisfecha [...] no hay barro, por vil y despreciable que sea, del que, puesto en sus divinas manos, no pueda hacer [Dios] un vaso de elección. Así lo siento.

En el convento de La Merced de Logroño, 2 de agosto de 1781.

Tomás Velasco, comendador. [rúbrica]

Ante la disparidad de criterios, el licenciado Ortega - fiscal del Santo Oficio ${ }^{19}$ escribe el 8 de agosto al Inquisidor General para pedir la opinión de un tercer calificador (mostrando de paso la suya propia, desfavorable a la comedia):

\section{Muy llustre Señor:}

El Inquisidor fiscal de este Santo Oficio [...] digo: que los dos calificadores que la han reconocido están opuestos en un todo. El uno la considera llena de proposiciones heréticas, erróneas, impías, escandalosas, temerarias, etc., y el otro juzga que no contiene dicho ni hecho alguno por el que se pueda presumir que su lectura sea perjudicial [...] Así lo siente el Padre Comendador, cuyo dictamen merece mucho respeto por la literatura, juicio y cristiandad de este prelado; pero el fiscal no puede aquietarse con este parecer, ni le convencen las pruebas en que viene fundado [...] Pero más bien se conocerá la necesidad de prohibir esta comedia remitiéndola a la censura de un tercero calificador, que es lo que debe hacerse en la insinuada discordia; y así lo pido. V.S. acordará lo que juzgare oportuno. Secretario de la Inquisición de Logroño, 8 de agosto de 1781.

Licenciado Ortega. [rúbrica]

19. «El inquisidor-fiscal, que solía ser el inquisidor más antiguo del tribunal, podía ser -como en el caso del secretario o notario del secreto y debido a la complejidad del cargo en cuestión-, de varias clases según el ejercicio y sueldo: numerario, supernumerario, interino, etc.» (Muñoz García, 2005, p. 157, n. 25) 


\section{UN VIEJO ARGUMENTO: «MÁS DAÑO HIZO LOPE»}

El mismo 9 de agosto, nada más recibirse la carta del fiscal Ortega, se encomendó la tercera censura al prior del monasterio cisterciense de Santa María de Valbuena (Valladolid), fray Martín de Larrayoz, quien firmó el día 18 de ese mes su informe, claramente desfavorable. El prior Larrayoz recurrió incluso a censores de mediados del siglo XVII para arremeter contra el teatro de Lope, citando una frase de fray Pedro de Tapia sobre el daño irreparable que había hecho el Fénix en España con sus comedias:

De orden del Santo Oficio de la Inquisición de Logroño he leído una comedia intitulada La fianza satisfecha, su autor Lope de Vega Carpio; y a su vista ya no extraño el dicho de aquel celoso y gran prelado, el ilustrísimo señor doctor fray Pedro de Tapia, del orden de los Predicadores: que más daño hizo Lope de Vega con sus comedias en España que Lutero con sus herejías en Alemania. [...] Ya veo que todo esto es pura representación del papel que hace el cómico, y no expresión del sentir y afecto del autor; pero si hemos de creer a los Santos Padres, y aún a la misma lastimosa experiencia, es poner lazos a las almas e inducirlas a los males que se representan [...] Por todo lo cual, y mucho más que pudiera notar, juzgo que es execrable esta comedia. Salvo, etc.

Nuestra Señora de Valbuena, y agosto 18 de 1781.

Fray Martín de Larrayoz, presentado y prior. [rúbrica]

El fiscal Ortega concluye (con fecha de 23 de agosto) que la comedia debe prohibirse por lo que dicen los calificadores primero y tercero, ya que el segundo -como ya advirtió en su propio escrito anterior del día 8, al que remite- es muy benévolo:

\section{Autos}

Muy Ilustre Señor:

[...] V.S. se ha de servir declarar que hay motivos bastantes para prohibirla y recogerla, por contener las proposiciones heréticas, erróneas, etc., que insinúan las censuras de los Padres Larrayoz y Ruiz Pascual, sin embargo de lo que dice la otra del Padre Velasco; la cual es benigna con exceso y no puede seguirse, por las razones expuestas en mi anterior escrito, que reproduzco en esta parte. V.S. acordará lo que fuere de su agrado.

Secretario de la Inquisición de Logroño, 23 de agosto de 1781.

Licenciado Ortega. [rúbrica]

El documento se presenta el 30 de agosto y parece que ese mismo día ve el expediente completo - en audiencia privada - otro inquisidor, quien dice que la comedia debe prohibirse y que se mande al Consejo (única institución capacitada para tomar la decisión final). El secretario Soto certifica - sin fecha- todas las diligencias: 
Y vistos por otro señor inquisidor (que asiste solo) en audiencia del mismo día, dijo que con reflexión a las censuras dadas a la comedia intitulada La fianza satisfecha, su autor Lope de Vega Carpio, le parece ser digna de prohibirse; para cuyo efecto se remita a los señores del Consejo. Y lo rubricó; de que certifico.

Marcos José de Soto y Olaso, secretario. [rúbrica]

\section{UNA CENSURA PEER-REVIEWED A CIEGAS}

Sin embargo, el Consejo todavía ordenará que se remita a nuevos calificadores para que emitan su opinión sobre cada uno de los aspectos tocados en las censuras anteriores; parece que la diligencia se hizo el 19 de septiembre, o bien que ese día se recibió el informe solicitado, que lleva esa misma fecha:

En el Consejo a 15 de Septiembre de 1781.

Su Excelencia y los señores Sánchez, Urríes, Otero, Escalzo, y Loigorri. Remítase por la secretaría a los padres calificadores mercedarios descalzos para su calificación con copia de las censuras supressis nominibilis. [rúbrica] Advirtiéndoles que den la suya sobre cada una de las proposiciones, en particular de dicha comedia, que fueren dignas de ella. [rúbrica]

[¿Fecho?] en 19. [rúbrica]

Repárese en que la encomienda del Consejo a los calificadores mercedarios se acompaña de copias de las censuras anteriores, para que contesten a cada punto que se menciona en ellas, pero omitiendo los nombres de sus firmantes para no condicionar ni predisponer el juicio de los nuevos informantes ${ }^{20}$. El procedimiento (similar a la revisión de los artículos por pares ciegos que hoy en día se hace en las publicaciones científicas) dio como resultado la censura más interesante de todo el expediente.

Se trata de un documento extensísimo (casi cuatro folios por ambas caras), que hemos tenido que reducir drásticamente para incluirlo en estas páginas, donde sus firmantes critican a dos de los calificadores anteriores por hacer censuras a bulto (es decir, «sin separar una cosa de otra, poco mas o menos y, como se suele decir, a ojo y sin formar jucio por menor y con distinción cabál de las cosas»; Autoridades, 1726) y por desatender una bula papal que obligaba a justificar con los pasajes textuales pertinentes las prohibiciones de obras ${ }^{21}$.

20. «Hecha una primera calificación, el tribunal manda que la obra cuestionada y las exposiciones precedentes, sin indicación de su autor, se pasen a un segundo censor para que realice la misma operación, y emita asimismo informe o dictamen sobre los textos que le someten o presentan. Cada calificación no suele encomendarse a un solo personaje, sino a él y a otro teólogo que él mismo quiera elegir o en quien el mismo confíe - «a alguien de su confianza», o «a alguien de su elección»-. Ambos examinan el libro y las anteriores calificaciones, dan su censura juntos, y la firman también juntos si es acorde y unánime» (Muñoz García, 2005, p. 158).

21. El papa ilustrado Benedicto XIV reformó en 1758 el Índice de libros prohibidos. Antes, el 9 de julio de 1753, se había publicado su Bulla Sollicita ac Provida, a la que se van a referir los calificadores de La 
Los censores del madrileño convento de Santa Bárbara firman el 19 de octubre su extenso y detallado informe (como les había pedido el secretario Bertrán), donde sostienen que no hay razones para prohibir la comedia, pese a lo que dicen las censuras previas:

\section{Muy Poderoso Señor:}

Por el secretario don Matías Bertrán hemos recibido de orden de V.A. una comedia de Lope de Vega Carpio cuyo título es La fianza satisfecha; y también las tres censuras que se han dado sobre ella.

Hemos examinado todo con el debido cuidado, y somos de parecer con el segundo calificador, que no hay motivo alguno que obligue a V.A. a prohibir esta comedia. También reconocemos con el mismo calificador segundo que, leída o representada en el teatro puede ser de utilidad [...] Si Lope de Vega hubiera dispuesto otra comedia con los personajes y máximas de estos impíos de la Escritura [...] no hay duda que el calificador primero, principalmente, le hubiera descargado cien veces toda la metralla de su censura. Pero así como en este caso solo sería en verdad palo de ciego, también debemos contemplarla del mismo modo en este otro de Leonido [...]

No hay en toda ella expresión alguna de Leonido blasfema, cruel, lasciva, inhumana, o de otro modo desordenada, a la que el autor no adjunte inmediatamente, por boca del gracioso Tizón, la más cristiana corrección y las más justa censura [...]. En todo caso, es muy de notar que no se hubiese arreglado en su censura a la instrucción del Santo Benedicto XIV en su Bulla solicita ac provida, cuando dispone que el calificador censuram suam cripto consignet, locis indicatis et paginis in quibus notati errores continenter. A la verdad, muy poderoso señor, censuras a bulto, son de poco momento.

La censura del calificador tercero -aunque más moderada-, atendido a lo expuesto, nos parece no hace fuerza. La autoridad del Angélico Maestro ${ }^{22}$ con el Crisóstomo es innegable en el caso del que oye o lee una comedia [...] Nada de esto hay en la comedia que se censura. Y por lo que respecta a provocar o no a la lascivia, puede asegurarse que tal comedia es de las más puras, porque en ella nada hay de aquellas alcahueterías, graciosidades, chuladas y porquerías que en otras muchas.

Por lo que respecta a la veneración que tributan a Leonido pendiente en la cruz por Jesucristo, su padre y sus dos hermanas, Marcela, y Lidora; y que el calificador tercero califica por abominable, mirada a fondo decimos: lo primero, que la tal veneración es de tramoya ${ }^{23}$; lo segundo que, correspondiendo bien, como de hecho corresponde a la cosa representada, nada tiene de abominable ni de viciosa. Represéntase un mártir padeciendo por Cristo, a vista de todo un público. Esto no es malo [...] Por tanto no puede dudarse que la representación está dispuesta con arreglo a los principios católicos. Este es nuestro juicio, que sujetamos en todo al siempre más recto de V.A.

Merced.

22. Santo Tomás de Aquino, el Doctor Angélico, cuya Summa Theologica [2.2.g.167, part. 2 ad.2] había citado el censor de Santa María de Valbuena, fray Martín de Larrayoz, en su ataque contra la comedia (citas que hemos suprimido para aligerar el texto).

23. «Enredo hecho con ardid y maña, o apariencia de bondad» (Diccionario de Autoridades, 1726). 
En este de Santa Bárbara y octubre hoy 19 de 1781.

Fray Antonio de la Santísima Trinidad, calificador. [rúbrica]

Fray Francisco de San Joaquín, calificador. [rúbrica]

«The process seems to have come to an end with their opinion», señalan Whitby y Anderson: "Their arguments in defense of La fianza satisfecha must have been convincing to the members of the Council» ${ }^{24}$. Ese dictamen se recibe «en el Consejo a 22 de octubre de 1781. / (S.C. pres. ${ }^{\mathrm{te}}$ )», se traslada «al relator» y el día 23 lo ven los consejeros: «En el Consejo a 23 de octubre de 1781. / Su Excelencia y los señores Sánchez, Otero, Escalzo y Loigorri. / Visto. [rúbrica]».

\section{UN EXPEDIENTE CON MUCHAS IRREGULARIDADES}

Una nota en la segunda hoja del expediente habla de un «decreto del Consejo de 22 de octubre de 1781. Visto», pero no parece contenerse aquí: «We have not seen the decree referred to, but it must have been favorable to the play's continued existence» ${ }^{25}$. Es decir, nos encontramos (y es el primer motivo de extrañeza de este expediente inquisitorial) ante la ausencia de respuesta final, una especie de silencio administrativo o sobreseimiento del que cabe tal vez colegir que la obra no fue finalmente prohibida tras su revisión por la Inquisición entre junio y octubre de 1781. Hay que tener en cuenta, no obstante, que «la mayor parte de los expedientes de condenación de libros conservados en los archivos de la Inquisición del siglo XVIII son incompletos. Algunos de ellos, sin embargo, permiten seguir la marcha del procedimiento» ${ }^{26}$.

Sí terminó con prohibición inquisitorial, en cambio, la reapertura del caso de La fianza satisfecha en Barcelona, en 1798 (sin que conste denuncia). El 3 de febrero la Inquisición de Barcelona pide su censura (reflexiva, pero rápida) a los calificadores Camarasa y Calveria:

Remitimos a nuestros calificadores padres Mariano Camarasa y fray Antonio Calveria la adjunta comedia intitulada La fianza satisfecha para que, vista y examinada con la reflexión que corresponde, formalicen su censura exponiendo su dictamen en orden a si puede permitirse su representación y lectura, o si debe corregirse y enmendarse o prohibirse en un todo.

Evacuada con la posible brevedad y que permitan a Vuestra Reverencia sus ocupaciones, nos la remitirán devolviendo esta comisión y dicha comedia. Nuestro Señor que etc.

Inquisición de Barcelona y febrero 3 de 1798.

Doctor don Pedro Díaz de Valdés. [rúbrica]

24. Whitby y Anderson, 1971, pp. 50 y 56.

25. Whitby y Anderson, 1971, p. 50.

26. Defourneaux, 1973, p. 57, n. 24

HIPOGRIFO, 5.1, 2017 (pp. 445-463) 
Licenciado don Manuel de Mena y Paniagua. [rúbrica]

Doctor don Ciro Valls y Geli, secretario. [rúbrica]

A nuestros calificadores, reverendos padres fray Mariano Camarasa y Fray Antonio Calveria.

Una semana después, el 11 de febrero de 1798, firman los calificadores Camarasa y Calveria su informe (desfavorable a la comedia), que se recibe en la Inquisición el 13 de febrero y que plantea un nuevo problema: los ecos de Cristo ${ }^{27}$. Ese mismo día el fiscal del Santo Oficio dice que se prohíba y se recojan los ejemplares:

\section{Muy Ilustre Señor:}

Hemos recibido la de Vuestra Señoría con la adjunta comedia intitulada La fianza satisfecha, que nos manda Vuestra Señoría censurar; y, después de haberla leído con toda reflexión [...] juzgamos unánimes, los dos infraescritos, que no debe permitirse su representación ni su lectura, por ser ofensiva a los piadosos oídos, inductiva a una vana presunción y poder inducir a los incautos muchas maldades; y, por ultimo, por la impropiedad de los ecos de Cristo. Ese es nuestro parecer, salvo siempre el de Vuestra Señoría. Dios guarde a V.S. muchos años.

Barcelona y febrero 11 de 1798.

Fray Mariano Camarasa.

Fray Antonio Calvaria.

Presentada en 13 febrero de 1798.

Señores Sierra [y] Valdés.

Al señor inquisidor fiscal. [rúbrica]

Muy Ilustre Señor:

El fiscal de este Santo Oficio, en vista de la censura de los calificadores convenidos, le parece no solo que no debe permitirse la representación, sino que ni aún su lectura, por lo que podrá V.S. acordar no se represente [a S.A.] y ver cómo recoger las que quizás anden repartidas. V.S. determinarán lo que sea de su agrado.

Cam. ${ }^{a}$ y secretario de Barcelona a 13 de febrero año de 1798.

Doctor Quijano. [rúbrica]

Sin embargo (y es una nueva rareza), esta última nota de Quijano - escrita al margen izquierdo, bajo las anotaciones de registro de entrada del 13 de febrero y la remisión al fiscal- presenta debajo otra anotación de mano distinta que dice «Pres. ${ }^{\circ}$ en 12 Diciembre»; parece una nota incompleta, pero tiene un símbolo a modo de flecha que remite al vuelto del mismo folio, donde se ve el mismo símbolo y continúa la nota: «de 1799 / SS / Mena / Amarilla / Autos / [rúbrica]». Es decir, la nota completa dice lo siguiente: 
Presentado en 12 diciembre de 1799

Señores Mena [y] Amarilla.

Autos. [rúbrica]

Como puede apreciarse, hay un extenso lapso temporal entre la propuesta de prohibición del fiscal (13 de febrero de 1798) y esta nota de presentación del documento a Mena y Amarilla (12 de diciembre de 1799): nada menos que 22 meses. Pero el problema no acaba ahí, sino que las irregularidades del expediente continúan.

Creemos que esta última nota es de la misma mano e idéntica rúbrica (muy característica) que el texto que reproducimos a continuación, firmado por el secretario Ciro Valls; no lleva fecha, pero dice que lo vieron «los dichos señores inquisidores» (Mena y Amarilla) la mañana de ese mismo día (12 de diciembre de 1799) y que dijeron que, conforme a lo que habían dicho los calificadores y el fiscal, la comedia debía prohibirse; pero que antes viese el expediente el Consejo:

Y vistos por dichos señores inquisidores en su audiencia de la mañana del mismo día, mes y año, dijeron conformes que, en vista de las censuras de los calificadores y expuesto por el Inquisidor Fiscal, se prohíba la representación y lectura de la expresada comedia intitulada La fianza satisfecha de Lope de Vega Carpio. Pero que antes se remitiese a S.A. y señores del Consejo. Y lo rubricaron, de que certifico.

Doctor don Ciro Valls i Geli, secretario. [rúbrica]

[Otras dos rúbricas distintas de la de Valls]

Sin embargo, advertimos otra circunstancia extraña: la nota de esos otros dos censores (que supuestamente asumían la opinión de los anteriores de que debía prohibirse) no lleva esa fecha del 12-12-1799, sino nada menos que del 24-101800, diez meses más tarde, y hace referencia a que incluían su propio informe a continuación del de los calificadores Camarasa y Calveria, informe que sin embargo - nueva irregularidad - no figura. Esta nota, ubicada al final del legajo, dice lo siguiente:

Muy poderoso señor:

Remitimos a V.A. en dos hojas útiles la comedia intitulada La fianza satisfecha, de Lope de Vega Carpio, con la censura que sobre ella han dado los reverendos padres calificadores fray Francisco Camarasa y fray Antonio Calvería, religiosos del Carmen Calzado; y nuestro parecer a su continuación. Como V.A. se servirá mandar ver, y a nosotros lo que debamos ejecutar. Nuestro Señor guarde a V.A. etc.

Palacio de la Inquisición de Barcelona y octubre 24 de 1800.

Don José de Amarilla y Huertos. [rúbrica]

Licenciado don Manuel de Mena y Paniagua. [rúbrica]

En el Consejo a 31 de octubre de 1800. 

S. Pte
Al Relator. [rúbrica]

Adviértase que los inquisidores de Barcelona Mena y Amarilla firman el 24 de octubre de 1800 (recordemos que supuestamente, según el fiscal Valls, se les pasó el caso el 12-12-1799 y lo vieron ese mismo día) y que su informe, junto con el resto del expediente, está en Madrid, en el Consejo, el 31 de octubre, una semana después. Volveremos enseguida a esta nota, cuya autenticidad se nos antoja dudosa; pero sigamos antes con el recorrido cronológico por todas las notas del expediente.

Debajo de la nota de Valls del 12-12-1799 que transcribíamos arriba aparece esta otra, de mano distinta, fechada casi un año después (4 de noviembre de 1800) en el Consejo de Castilla (Madrid), donde se remite a la Junta:

En el Consejo a 4 de noviembre de 1800.

Señores [?], Cantera, Consuegra, Nubla, [?], Cuerda, Ovando, Hevia, Salazar

A la Junta en la forma ordinaria para que diga su dictamen. [rúbrica]

El 9 de noviembre se comunicó esa petición de dictamen a la Junta, que lo firmó con fecha 12 de noviembre de 1800 (se recibió de vuelta en el Consejo el día 20). La Junta propuso la prohibición de representar y leer la comedia; su dictamen (escrito por el primero de sus siete firmantes, fray Antolín Merino) se expresa en términos tajantes, replicando a los irónicos censores que defendían la idoneidad de La fianza satisfecha:

\section{Muy Poderoso Señor:}

De orden de V.A., comunicada a la Junta en 9 del corriente, hemos visto y examinado la comedia intitulada La fianza satisfecha, obra - según parece- del poeta (bien conocido) Lope de la Vega Carpio. Hemos visto también la censura que la acompaña de los calificadores, la cual en pocas palabras dice cuanto basta para hacer ver que no solo se debe prohibir la representación de esta comedia, sino también su lectura, por perjudicial a las buenas costumbres e inductiva a una vana confianza.

[...] Ademas, lo que resalta en esta composición (y es como el blanco de ella) se reduce a la expresión que tantas veces repite el héroe, manchándola entre sus blasfemias; esto es: «Que lo pague Dios por mí» (lo que da motivo al título de La fianza satisfecha). [...] Si esto no es profanar lo más sagrado y hacer ridículo lo más serio y más grave del Evangelio, no sabemos qué otra cosa lo será.

Por tanto, la Junta es de parecer que se prohíba no solo la representación sino aún la lectura de dicha comedia con la nota referida al principio; si es que a V.A. no pareciere otra cosa, que siempre será lo más acertado.

Madrid y noviembre 12 de 1800.

Fray Antolín Merino. [rúbrica]

Licenciado don Ángel Gutiérrez de Santa Clara. [rúbrica] 
Fray Jacobo Vivanco. [rúbrica]

Vicente Ramírez. [rúbrica]

Fray Tomás Muñoz. [rúbrica]

Fray Ramón Desojo. [rúbrica]

Joaquín Lorenzo Villanueva. [rúbrica]

El dictamen de la Junta se registra en el Consejo «a 20 de noviembre de 1800». Nueve días después, se publica el edicto de prohibición de la representación y lectura de La fianza satisfecha. Debajo, una nota de mano distinta señala la fecha del edicto, marzo de 1801 :

Al relator. [rúbrica]

En el Consejo a 29 de noviembre de 1800.

Señores Cantera, Consuegra, Nubla, [?], Cuerda, Ovando, Hevia, Salazar.

Que se prohíba en primer edicto la lectura y representación de esta comedia por ser perjudicial a las buenas costumbres e inductiva a una vana confianza. [rúbrica]

Edicto de marzo de 1801, nº 18, clas. $2^{\text {a28 }}$.

Volvamos ahora un poco atrás, al momento en que el secretario Valls dice que el 12 de diciembre de 1799, tras registrarse la entrada del expediente (que, recordemos, llevaba circulando desde el 13 de febrero de 1798) y la entrega del mismo a Mena y Amarilla, «los dichos señores inquisidores» deciden esa misma mañana, a la vista de lo que decían los anteriores calificadores y lo que exponía el fiscal, proponer la prohibición y la remisión del asunto al Consejo.

Pero ya hemos visto que su documento (si es que es de Mena y Amarilla) está firmado en realidad a 24 de octubre de 1800 (no a 12 de diciembre de 1799) y dicen que mandan también su propio dictamen adjunto al de Camarasa y Calveria y la propia comedia («nuestro parecer a su continuación»), que sin embargo no aparece por ninguna parte.

La clave, a nuestro entender, está en la letra de esta nota firmada por Mena y Amarilla, donde creemos ver en realidad la mano del secretario Ciro Valls. El texto propiamente dicho es de su mano con total seguridad; las firmas que lo acompañan tal vez también, aunque no podemos pronunciarnos tajantemente: son muy distintas entre sí, y distintas a su vez a la de Valls de más arriba. Pero las que sí parecen muy distintas son las respectivas rúbricas que acompañan a sus firmas; curiosamente, estas dos rúbricas son muy semejantes a esas otras que iban debajo de la nota de Valls del 12-12-1799. Es decir: o bien Valls falsificó todo, o bien Mena y Amarilla le rubricaron (sin firma) bajo la nota de Valls del 12-12-1799 (donde ya

28. En efecto, el Índice de los libros prohibidos por el Santo Oficio de la Inquisición recoge este edicto: «Vega Carpio (Lope de). Comedia. La fianza satisfecha. Edicto de 18 de Marzo de 1801» (Carbonero, Índice de los libros..., p. 656). 
dice Valls «Y lo rubricaron, de que certifico») y le firmaron (y rubricaron) una hoja en blanco al final del expediente para que él pusiera el 24 de octubre de 1800 lo que más conviniera al proceso.

Whitby y Anderson advirtieron de que «almost two years had gone by since the original censure. Now another ten months were to elapse before the play and the proceedings referring to it would be sent in Council on 4 November and was sent to the Junta for its judgement ${ }^{29}$. Pero no parecen haber reparado en esa contradicción en las fechas ni en la coincidencia de una misma mano en documentos firmados por personas diferentes.

Sin embargo, alguien de aquella época sí debió de darse cuenta de que las fechas no casaban, hasta el punto de que en la portada del expediente inquisitorial conservado en el AHN se consigna la siguiente (y muy importante) información, que supone la principal rareza del expediente:

Se suspende la remisión por la discordancia de fechas que se notan.

El apunte, que ninguno de los estudiosos de La fianza satisfecha menciona, es (con casi total probabilidad) de mano del propio doctor Ciro Valls, el secretario de la Inquisición de Barcelona; es decir, el mismo que (creemos) «falsificó» el texto de Mena y Amarilla, tal vez sin intención fraudulenta (solo para aligerar un mero trámite administrativo ${ }^{30}$ ) o bien con ánimo de salirse con la suya frente a los calificadores que se habían mostrado favorables a la comedia.

Una posible explicación de la suspensión que advierte la última nota citada es que alguien se diera cuenta de que faltaba el informe de dichos calificadores o advirtiera el lapso de 22 meses transcurrido y la falta de concordancia de las fechas que hemos señalado, decidiendo consecuentemente suspender la remisión. El secretario Valls, como encargado del asunto, hizo la pequeña trampa oportuna para permitir que el expediente siguiera su curso, porque parece que había un interés especial por parte de la Inquisición en prohibir La fianza satisfecha pese a que varios censores muy doctos habían sostenido con firmeza la idoneidad de la comedia, frente a los «palos de ciego» y las «censuras a bulto» de otros.

La truculenta obra atribuida a Lope se salvó (aparentemente) de la prohibición inquisitorial en 1781, pero un nuevo ataque del Santo Oficio en 1798 dio con sus

29. Whitby y Anderson, 1971, pp. 50-51.

30. Ver el expediente de censura del Quijote (descubierto hace poco también en el AHN), donde los investigadores dieron por autógrafa de Cervantes la solicitud de aprobación (pese a ciertas extrañezas caligráficas y ortográficas), pero finalmente descubrieron que lo que había detrás era la mano del editor Francisco de Robles, quien se dedicaba a preparar este tipo de diligencias censorias para que luego el autor solicitante solo tuviera que estampar su firma (esta sí, auténtica) bajo el cuerpo de la solicitud: «Era y es cosa general que los editores, no los autores, se ocupen en el papeleo administrativo. Está probado que Robles presentaba en el Consejo tasas ya parcialmente redactadas que los escribanos no tenían sino que completar y autorizar. La petición de licencia y privilegio caligrafiada por Robles y rubricada por Cervantes equidista, con cabal simetría, de ambas prácticas corrientes» (Bouza y Rico, 2009, p. 26). 
versos en el Índice de libros prohibidos tres años y un mes más tarde ${ }^{31}$, en una nueva victoria de los teatrófobos, que descargaron (como dijeron aquellos otros calificadores más tolerantes) «toda la metralla de su censura».

Un caso muy semejante (que citábamos a otros efectos al comienzo de estas páginas) ha estudiado hace pocos años Alicia López; se trata de El diablo predicador, de Luis Belmonte Bermúdez, también dramaturgo áureo ${ }^{32}$. A finales del siglo XVIII se prohibió la representación en Logroño de esta comedia, que acabaría por ser incluida en el Índice de libros prohibidos en 1804. La obra se había representado originariamente en 1623 y se publicó veinte años después en la Parte Sexta de Escogidas; surgieron dudas con respecto a la autoría de la obra (atribuida en algunos manuscritos a Francisco de Villegas), dudas que algunos estudiosos achacan a una voluntad autocensoria y al interés del propio autor por desvincularse de una obra políticamente conflictiva; así, Antonio Sánchez relaciona El diablo predicador con La gloria de Niquea y Siempre ayuda la verdad, casos de autocensura en que los dramaturgos, en aras de la preservación del contenido de sus obras, se veían obligados a desvincularse de ellas ${ }^{33}$.

En 1787, un sector de la Inquisición quiso prohibir El diablo predicador por ver en ella un cúmulo de "chocarrerías, amores profanos, uxoricidios y alcahueterías, blasfemias, herejías [...] y vilipendio del estado religioso» (aunque no faltaron calificadores que se pronunciaron a favor de su licitud); pero el Consejo de Castilla suspendió el expediente de prohibición en septiembre de 1790 y dio vía libre a la representación. Sin embargo, además de las actuaciones inquisitoriales en Logroño y la villa de Haro, se produjeron después en ciudades del sur de España, en 1801, otras denuncias contra esta comedia, que acabó en el Índice inquisitorial por edicto de febrero de 1804; así consta en otro expediente del AHN (descubierto por Alicia López) que viene a complementar (como en el caso de La fianza satisfecha) la información parcial que se tenía sobre El diablo predicador a partir de los trabajos de Paz y Mélia y Antonio Roldán: a resultas de la denuncia de un espectador del corral de comedias de Llerena contra el entremés Juanito y Juanita, de Ramón de la Cruz, se actuó contra la compañía de Antonio Pazo, que había representado esa pieza prohibida y que tenía también en su repertorio obras del corte de El convidado de piedra, El rosario perseguido, El diablo predicador y, precisamente, La fianza satisfecha.

Sin duda, fueron las célebres prohibiciones decretadas a finales del siglo XVIII contra ciertos géneros teatrales (las comedias de santos, las de bandoleros, los sainetes) las que sirvieron como acicate para la denuncia a la Inquisición de este grupo de obras. Pero, por otra parte, estos casos suponen una nueva muestra de la intensa revisión censoria del teatro barroco en aquella época, cuando los guardianes de la moral hubieron de revisar muchísimas obras que habían sido representadas sin problemas en el siglo XVII por culpa de la proliferación de denuncias (aun-

31. «La duración normal de una sumaria inquisitorial de censura [era de] dos años y medio aproximadamente» (Muñoz García, 2005, p. 160).

32. López de José, 2011.

33. Sánchez Jiménez, 2001. 
que muchas veces quedaban en simples intentos de prohibición que solo servían para hacer perder el tiempo a los censores).

\section{BIBLIOGRAFÍA}

Alcalá, Ángel, Literatura y ciencia ante la Inquisición española, Madrid, Laberinto, 2001.

Álvarez Faedo, María José, «La fianza satisfecha (atribuida a Lope de Vega) y su polémica acogida en España e Inglaterra», Castilla, 25, 2000, pp. 7-30.

Bouza, Fernando y Francisco Rico, «Digo que yo he compuesto un libro intitulado El ingenioso hidalgo de la mancha», Cervantes. Bulletin of the Cervantes Society of America, 29, 1, 2009, pp. 13-30.

Cañete, Manuel, Sobre el drama religioso español antes y después de Lope de Vega, Madrid, Librerias de A. Durán, 1870.

Carbonero y Sol, León, Índice de los libros prohibidos por el Santo Oficio de la Inquisición española, desde su primer decreto hasta el último, que expidió en 29 de mayo de 1819, y por los reverendos obispos españoles desde esta fecha hasta fin de diciembre de 1872, Madrid, Imprenta de Antonio Pérez Dubrull, 1873.

Defourneaux, Marceline, Inquisición y censura de libros en la España del siglo XVIII, Madrid, Taurus, 1973.

Jiménez Salas, María, «Un comentario más a La fianza satisfecha», Fénix. Revista del tricentenario de Lope de Vega, 1635-1935, 5, 1935, pp. 583-607.

López de José, Alicia, «Diablo y bandolero. Censores y calificadores. Testigos y desterrados», en Dramaturgos y espacios teatrales andaluces de los siglos XVI-XVII. Actas de las XXVI Jornadas de Teatro del Siglo de Oro, ed. Elisa García-Lara y Antonio Serrano, Almería, Instituto de Estudios Almerienses, 2011, pp. 241-261.

Menéndez Pelayo, Marcelino, Estudios sobre el teatro de Lope de Vega. II (Obras completas), ed. Adolfo Bonilla y San Martín, Madrid, Librería de Victoriano Suárez, 1921, t. II, pp. 95-99.

Muñoz García, María José, «Inquisición, sexo y sexismo a fines del Antiguo Régimen», Revista de la Inquisición, 11, 2005, pp. 151-201.

Paz y Mélia, Antonio, Papeles de Inquisición. Catálogo y extractos, 1907; 2ª ed., Ramón Paz, Madrid, Archivo Histórico Nacional, 1947.

Rojas y Contreras, José de, Historia del colegio viejo de San Bartolomé, mayor de la célebre Universidad de Salamanca, 2ª parte, t. 1, Madrid, Andrés Ortega, 1768.

Roldán Pérez, Antonio, «El diablo predicador: una comedia cuestionada. El Consejo de la Inquisición contra el Tribunal de Sevilla», en El centinela de la fe. Estudios jurídicos sobre la Inquisición de Sevilla en el siglo XVIII, coord. Enrique Gactor, Sevilla, Universidad de Sevilla, 1997, pp. 399-469. 
Sánchez Jiménez, Antonio, «Anonimia y censura en el teatro del siglo XVII: el caso de El diablo predicador», Hispanófila, 131, 2001, pp. 9-19.

Shack, Adolf Friedrich von, Historia de la literatura y del arte dramático en España, t. III, Madrid, M. Tello, 1887.

Valbuena Prat, Ángel, «Un personaje prefreudiano de Lope de Vega», Revista de la Biblioteca, Archivo y Museo del Ayuntamiento de Madrid, 8, 1931, pp. 25-35.

Whitby, William M. y Robert R. Anderson (ed.), Lope de Vega, La fianza satisfecha, Cambridge, Cambridge University Press, 1971 
